\title{
Experimental Analysis of Seepage in Soil Beneath a Model of a Gravity Dam
}

\author{
Najm Obaid Salim Alghazali ${ }^{1}$, Hala Kathem Taeh Alnealy ${ }^{2}$ \\ ${ }^{1}$ Corresponding author, Asst. Prof. Doctor, Civil Engineering Department, Babylon University, Iraq \\ ${ }^{2} \mathrm{M}$. Sc. Student, Civil Engineering Department, Babylon University, Iraq \\ Email address: \\ drnajm59@gmail.com (N. O. S. Alghazali), Halhhalh300@yahoo.com (H. K. T. Alnealy)
}

\section{To cite this article:}

Najm Obaid Salim Alghazali, Hala Kathem Taeh Alnealy. Experimental Analysis of Seepage in Soil Beneath a Model of a Gravity Dam. American Journal of Civil Engineering. Vol. 3, No. 3, 2015, pp. 64-69. doi: 10.11648/j.ajce.20150303.12

\begin{abstract}
In this research the experimental method by using Hydraulic modeling used to determination the flow net in order to analyses seepage flow through single- layer soil foundation underneath hydraulic structure. As well as steady the consequence of the cut-off inclination angle on exit gradient, factor of safety, uplift pressure and quantity of seepage by using seepage tank were designed in the laboratory with proper dimensions with two cutoffs. The physical model (seepage tank) was designed in two downstream cutoff angles, which are $\left(90\right.$, and $\left.120^{\circ}\right)$ and upstream cutoff angles $\left(90,45,120^{\circ}\right)$. After steady state flow the flow line is constructed by dye injection in the soil from the upstream side in front view of the seepage tank, and the equipotential line can be constructed by piezometer fixed to measure the total head. From the result It is concluded that using downstream cut-off inclined towards the downstream side with $\Theta$ equal $120^{\circ}$ that given value of redaction $(25 \%)$ is beneficial in increasing the safety factor against the piping phenomenon. Using upstream cut-off inclined towards the downstream side with $\Theta$ equal $45^{\circ}$ that given value of redaction $(52 \%)$ is beneficial in decreasing uplift pressure and quantity of seepage.
\end{abstract}

Keywords: Flow Net, Inclined Cutoff, Seepage Tank, Single Layer, Soil

\section{Introduction}

Hydraulic structures are a specific type of engineering structures designed and executed in such a way in order to control natural water or save industrial sources to guarantee optimum use of water. These structures are frequently build on soil materials and the foundation thickness must be thick so as to be safe against uplift pressure [1]. The differential head in water levels between the upstream and downstream acts on the foundation and causes seepage flow [2]. The Groundwater flow depends on the type of flow, the soil media, and the boundary conditions. Seepage of water is one of the main problems which effect on hydraulic structures [3] There are Different methods solution can be used to analysis the seepage problem such as experimental works using physical model as well as numerical models electrical analog models[4]. A flow net is in fact a solution of Laplace's equation in two dimensions. The model of seepage tank (sand tank)is very useful in studying the conditions of fluid flow under the hydraulic structure [5]. The paths taken by moving particles of water as the flow through a permeable material may be represented by a series of flow lines. These flow lines are nearly parallel curved lines The hydraulic modeling method to determine the flow net in this study represented by a physical model was built to study the phenomenon of seepage through soil.

\section{Aim of the Study}

The main objectives of this work can be summarized by the following points:

1. locate the equipotential lines and flow lines for singlelayer soil used in research work.

2. Study the effect of inclined cutoffs at different angles of inclination on exit gradient, uplift pressure underneath the hydraulic structure quantity of seepage and find the best inclination angle of cut-off for upstream and downstream side of hydraulic structure for all types of soils placed in different position under the foundation of hydraulic structure used in research work. 


\section{Experimental Work}

The results obtained by the present hydraulic model using the seepage tank that designed and carried out at the hydraulic laboratory of the Engineering College at Babylon University. The major purpose of the physical model adopted in the present research is to study the flow net and calculate the values of uplift pressure underneath the hydraulic structure, distribution of exit gradient, quantity of seepage for different types of soil at different position under the hydraulic structure foundation.

\subsection{Model Description}

Laboratory experiments have been conducted in a seepage tank that has been designed with hypnotically dimensions of $1.6 \mathrm{~m}$ long, $0.5 \mathrm{~m}$ width and $1.1 \mathrm{~m}$ height The bottom and sidewalls of this tank were made of Acrylic of $(10 \mathrm{~mm})$ thickness. Figure (1) shows the seepage tank used in present study (front view). The bottom of the tank was filled with this material of soil to a depth of $60 \mathrm{~cm}$. Acrylic walls were used to build the body of the superstructure which consists of two parts. The first part simulated as foundation of a structure $(40 \mathrm{~cm}$ long $\times 50 \mathrm{~cm}$ wide). This base is connected with the upstream and downstream cutoffs by gluing rubber strips. 10 piezometers were placed at the right side of the tank at different location. All piezometers are fixing to the board.

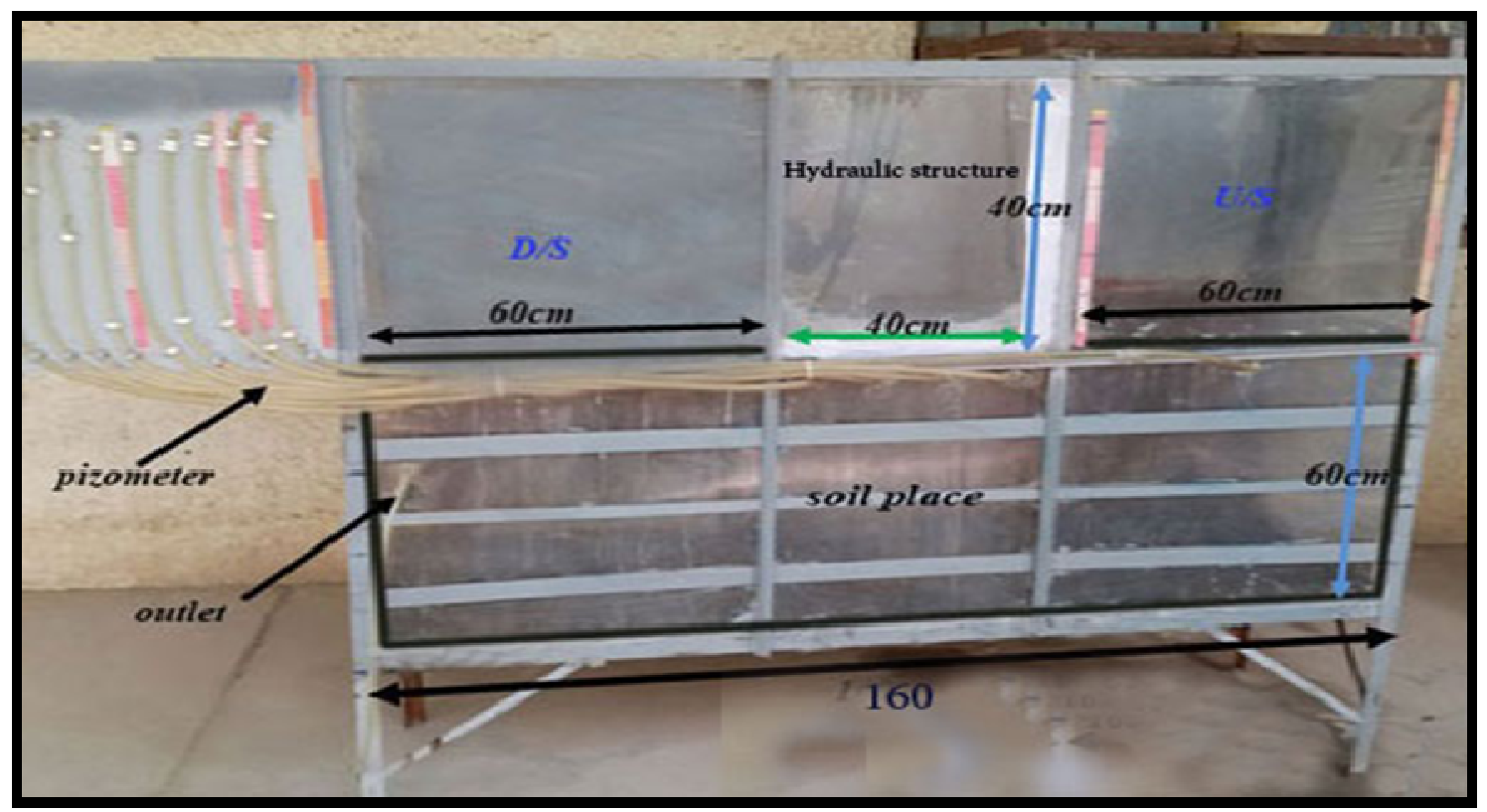

Figure (1). The seepage tank used in present study (front view).

\subsection{Engineering Properties of Soil Used in Research}

The experimental soil sample was taken from Hilla city region. The soil profile of any region contains many soil horizons, the difference between these horizons is marginal (no-homogenous soil). In the model tests, the profile is assumed to consist of one horizon (homogenous soil) [6]. The tests used here to analyze the soil specimen in order to determine soil distribution and other engineering properties were conducted as per the Unified Soil Classification System, also the hydraulic conductivity values of the soil samples was measured in laboratory method. Table 1 shows a summary of the physical properties that measured of the soils which consist of three layers arranged in descending order. Used in the present study. Figure (1) shown the arranged for type of soil used in present study.

Table (1). Physical properties of used soils.

\begin{tabular}{lllll}
\hline No of layer. & $\begin{array}{l}\text { Type off soil Arrange in } \\
\text { descending order }\end{array}$ & Void ratio & $\begin{array}{l}\text { Unit weight } \\
\text { KN/m3 }\end{array}$ & $\begin{array}{l}\text { Value of Hydraulic } \\
\text { Conductivity m/sec }\end{array}$ \\
\hline 1 & Sandy silty clay & 0.52 & 20.65 & 2.75 \\
\hline
\end{tabular}

\subsection{The Experimental Procedures}

Taking the datum to be at the bottom of the tank, Install the soil in the form of three layers each layer thickness of $0.2 \mathrm{~m}$ and it is monitoring the process of using. The metal cylinder.
Feeding the water to the seepage tank through the inlet hose until the water level in the upstream region reached the overflow hose level previously adjusted to meet the desired upstream water level.

After reaching steady-state flow dye is injected from dye 
bottles which placed in the specific points, after a period of time flow lines were drawn Flux, which represents how the flow of water within the soil particles

After drawing flow lines, the vertical piezometers were installed transparent glass vertically into the soil to measure the total head in the points to draw the equipotential line.

Measure the discharge of drained water collected from the downstream funnel using the volumetric method by using jar.

Record the reading of the piezometric head of all installed piezometers under the base and downstream side.
Put the cutoff at upstream side with the angle of inclination for upstream $(\Theta=45, \Theta=120, \Theta=90)$ and repeat the step (7-8-9) to find the best angle to gave less value of uplift pressure and quantity of seepage.

Put the cutoff at downstream side with the angle of inclination $(\Theta=90, \Theta=120)$ and repeat the step (7-8-9) to find the best angle to give max value factor of safety.

Table (2) shown the type of testing that made on multi layer soil

Table (2). The type of testing that made on soil.
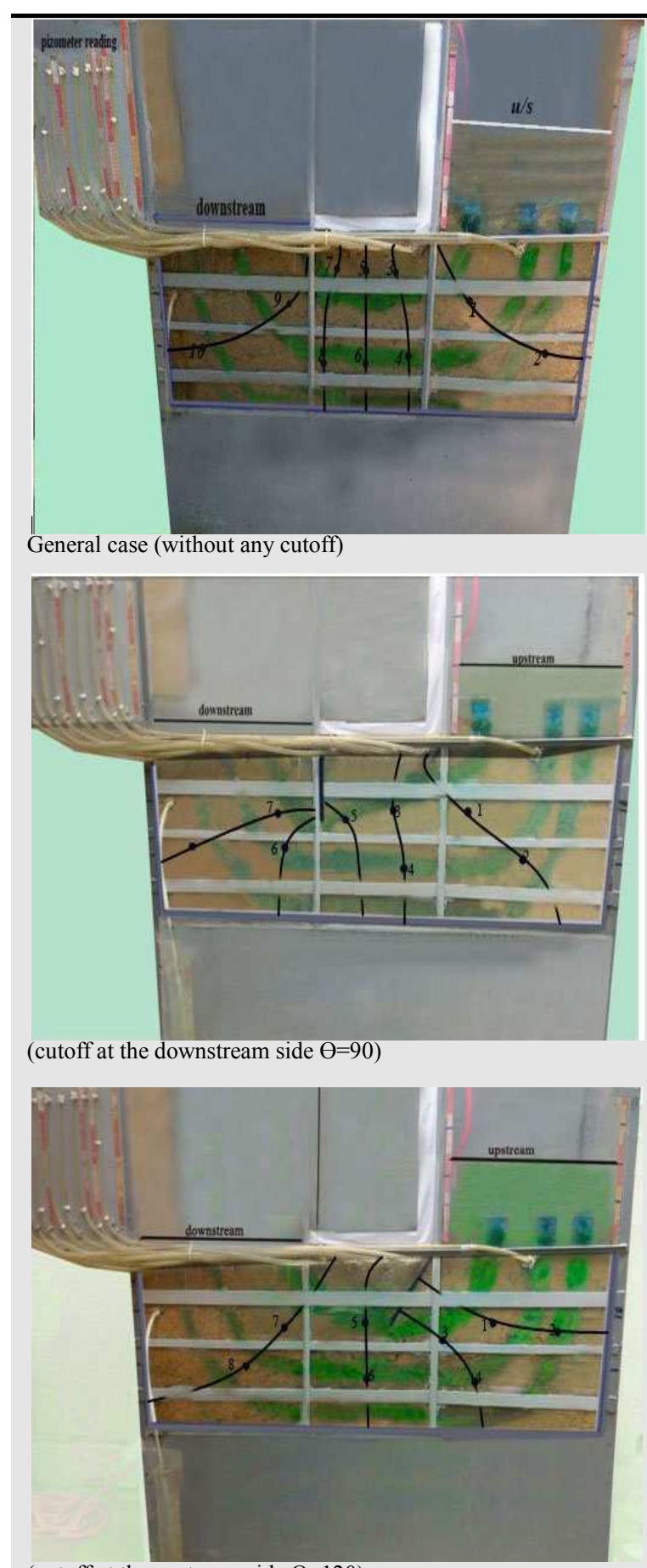

(cutoff at the upstream side $\Theta=120$ )

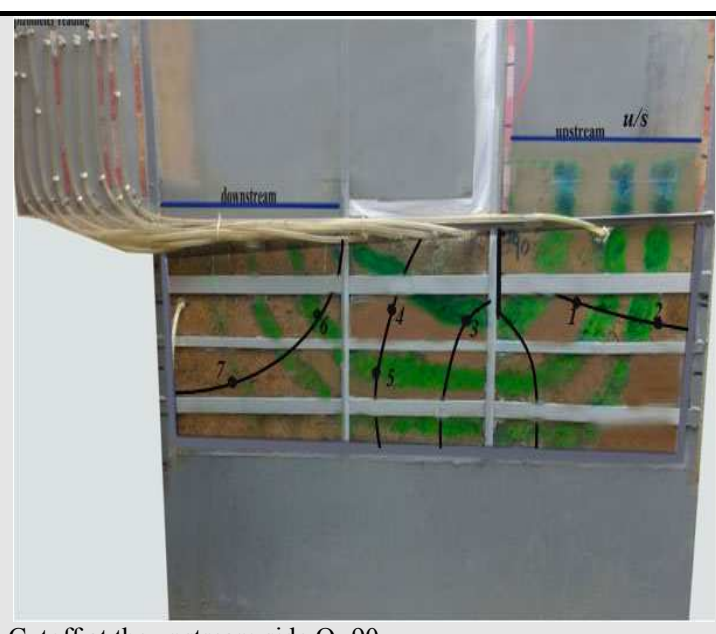

Cutoff at the upstream side $\Theta=90$

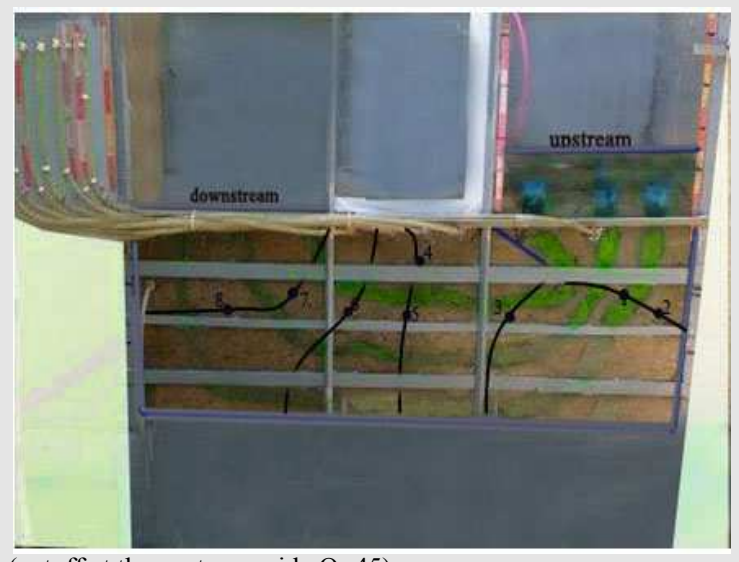

(cutoff at the upstream side $\mathrm{\Theta}=45$ )

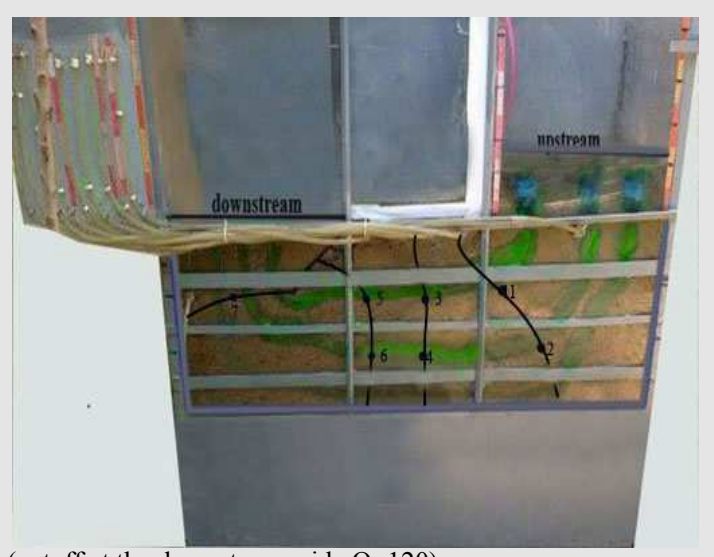

(cutoff at the downstream side $\Theta=120$ ) 


\section{The Results and Discussions}

Herein, the discussions of the results for single layer (sandy silty clay ) according the following parameters:

\subsection{Effect of Inclination Cutoff and its Position on the Uplift Head}

As shown in figure (2). When the Cutoff in upstream side of hydraulic structure was inclination with different angles, its noticed that the uplift pressure underneath the hydraulic structure decreases as $(\Theta)$ decreases toward $\mathrm{U} / \mathrm{S}$ side for $\Theta$ $\left(45^{\circ}, 90^{\circ}, 120^{\circ}\right)$ where the maximum redaction in uplift pressure according to the general case $\Theta=0$ (without any cutoff) was $(57 \%, 45 \%, 22 \%)$ respectively so that the best angle is $45^{\circ}$.

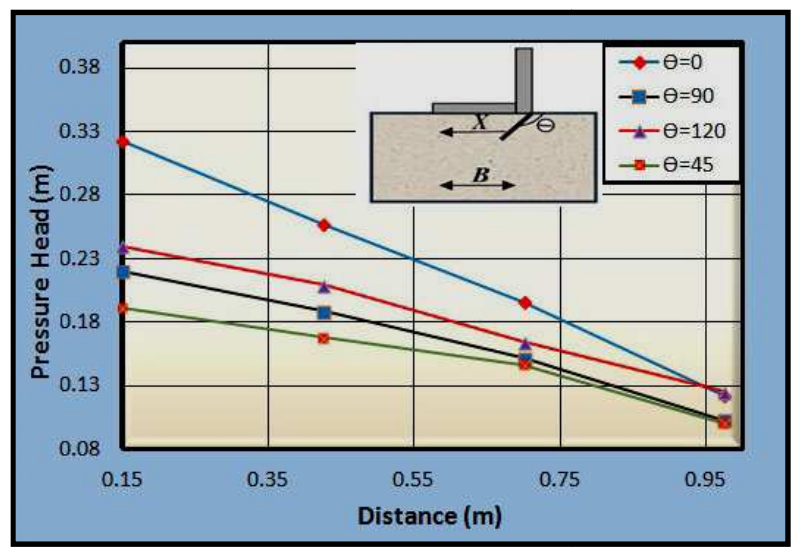

Figure (2). Uplift head ratio through foundation. A range of $(\theta)$ values for cutoff in $U / S$.

From figure (3). When the Cutoff in downstream side of hydraulic structure is used, the uplift pressure obtained decreases as $(\Theta)$ decreases toward $\mathrm{U} / \mathrm{S}$ side for $\Theta\left(90^{\circ}\right.$ and $120^{\circ}$ ) and the maximum redaction in uplift pressure according to the general case $\Theta=0$ was $(2.3 \%$, and $2.74 \%)$. It is noticed that the redaction of the uplift pressure is small to the replacing of the cut-off, therefore, it is not suggested at any angle of inclination.

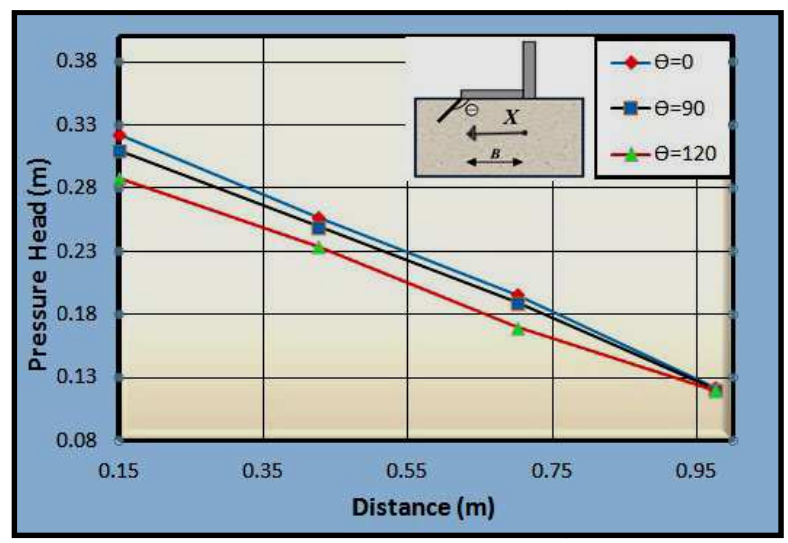

Figure (3). the value of uplift head for different values of $(\theta)$ values for cutoff in $D / S$ part of structure.
When the cutoff positioned in $\mathrm{U} / \mathrm{S}$ and $\mathrm{D} / \mathrm{S}$ part of structure as shown figure(4), the uplift reduced strongly and value of redaction is $38 \%$ as compared with general case $(\Theta=0)$.

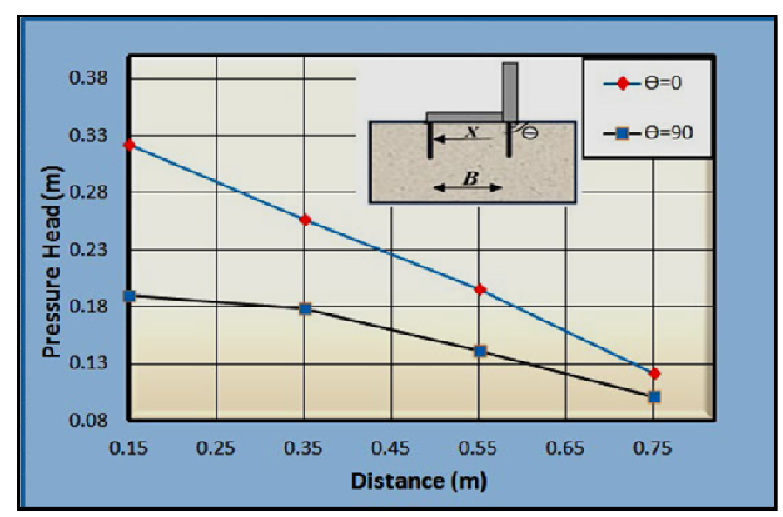

Figure (4). Uplift head ratio through foundation a range of $(\theta)$ values for cutoff in $U / S$ and $D / S$.

\subsection{Effect of inclination Cutoff and its Position on the Exit Gradient}

The exit gradient was studied at the end of the hydraulic structure for the cases that will be discussed herein and the results are represented graphically. The factor of safety for each angle of inclination must be calculated where is equal to the division of exit gradient on critical gradient (Icr) which is dependent on the specific gravity (Gs) and void ratio (e) of the soil particles [ Icr $=(\mathrm{Gs}-1) /(1+\mathrm{e})]$. In this study and for this type of soil ( $\mathrm{Gs}=2.75, \mathrm{e}=0.77$, Icr $=0.988)$.

In figure(5) when the cutoff put in upstream side of hydraulic structure it is found that the redaction in values of exit gradient were so small and as follows for $\Theta\left(45^{\circ}, 90^{\circ}, 120^{\circ}\right)$ where the maximum redaction in according to the general case $\Theta=0$ (without any cutoff) was $(1.2 \%, 1.87 \%, 2.47 \%)$ respectively

The result shows that the upstream cut-off inclination angle has no noticed effect on exit gradient. From the result the factor of safety against piping for this case were shown in table (3).

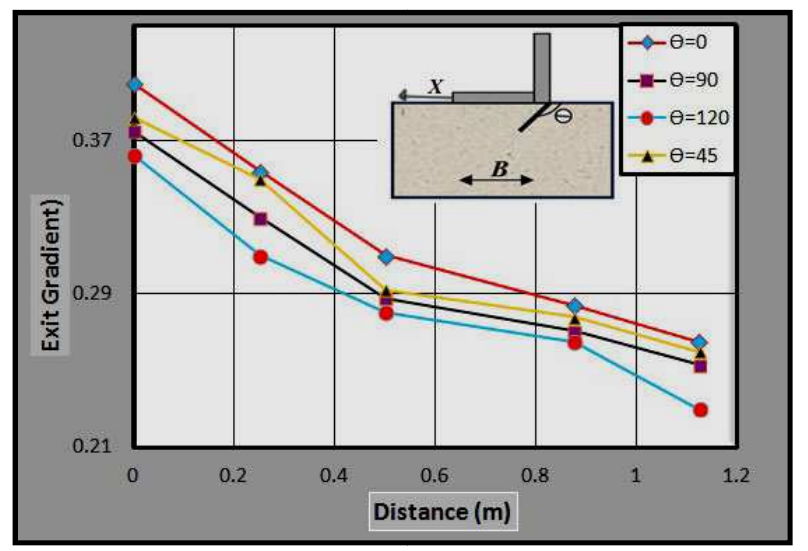

Figure (5). Exit gradient a range of $(\theta)$ values for cutoff in U/S part of structure. 
Table (3). The factor of safety against piping when cutoff at U/S.

\begin{tabular}{lll}
\hline U/S Cut-off Inclination & Max (exist gradient) & Fs \\
\hline $0^{\circ}$ & 0.4 & 2.47 \\
$45^{\circ}$ & 0.382 & 2.586 \\
$90^{\circ}$ & 0.375 & 2.63 \\
$120^{\circ}$ & 0.362 & 2.729 \\
\hline
\end{tabular}

In figure(6) when the cutoff is put it in downstream side of hydraulic structure the exit gradient decreases as $(\Theta)$ increases toward the $\mathrm{D} / \mathrm{S}$ side for $\Theta\left(90^{\circ}\right.$ and $\left.120^{\circ}\right)$ the maximum redaction in exist gradient according to the general case $\Theta=0$ was $(12.5 \%$ and $25 \%)$, respectively. So that the factor of safety against piping phenomenon of this case can be calculated as shown in table (4). These results show that using cutoff in $\mathrm{D} / \mathrm{S}$ side inclination toward $\mathrm{D} / \mathrm{S} \quad \mathrm{\theta}=120$ increasing the factor of safety against piping.

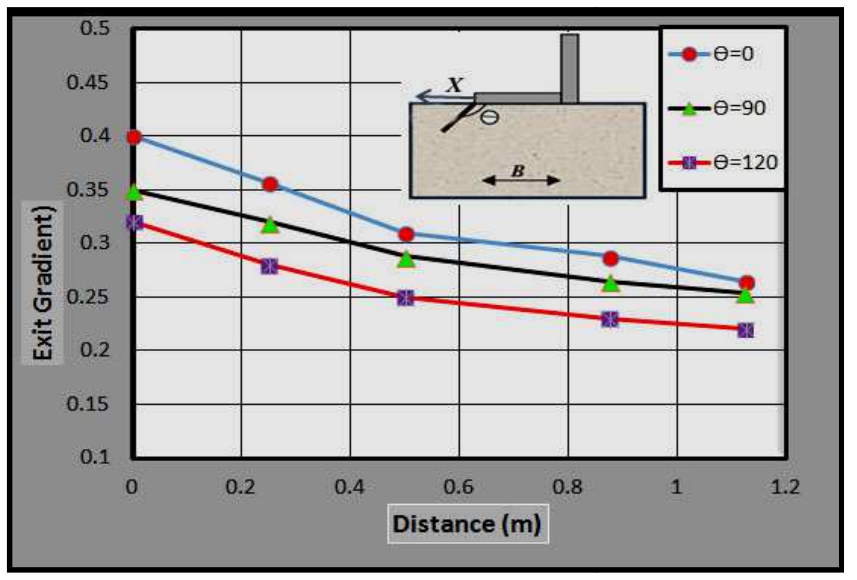

Figure (6). Exit gradient a range of $(\theta)$ values for cutoff in U/S part of structure.

Table (4). The factor of safety against piping when cutoff at U/S.

\begin{tabular}{lll}
\hline U/S Cut-off Inclination & Max (exist gradient) & Fs \\
\hline $0^{\circ}$ & 0.4 & 2.47 \\
$90^{\circ}$ & 0.35 & 2.82 \\
$120^{\circ}$ & 0.31 & 3.18 \\
\hline
\end{tabular}

When the Cutoff in up and down stream side of structure the exit gradient in the bed level of structure decreases compare with general case as shown in figure (7).

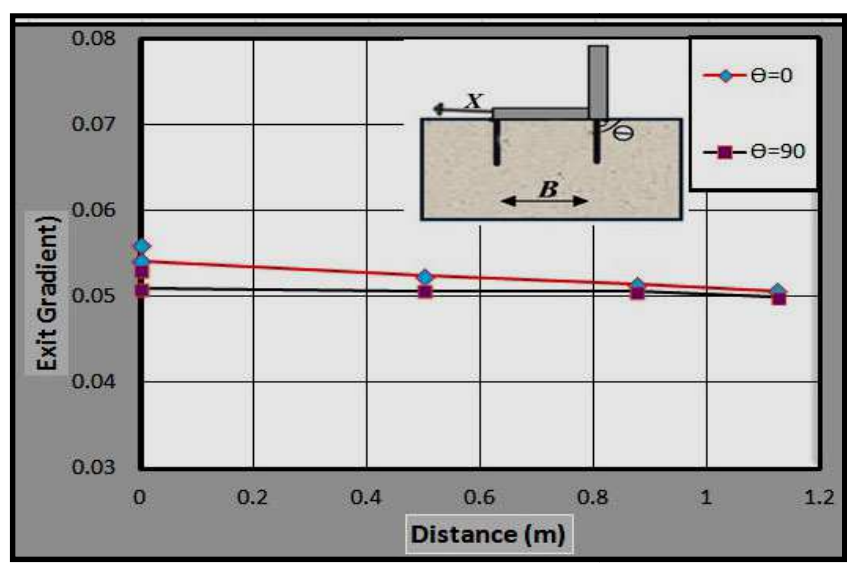

Figure (7). Exit gradient a range of $(\theta)$ values for cutoff in U/S part of structure.

\subsection{Effect of Cutoff Position and Inclination on the Seepage Quantity}

When the Cutoff is in upstream side of hydraulic structure, as shown in figure(8), it's found that the seepage decreases while $(\Theta)$ decrease toward $\mathrm{U} / \mathrm{S}$, and the least quantity of seepage occurred when $(\Theta)$ value around (45).

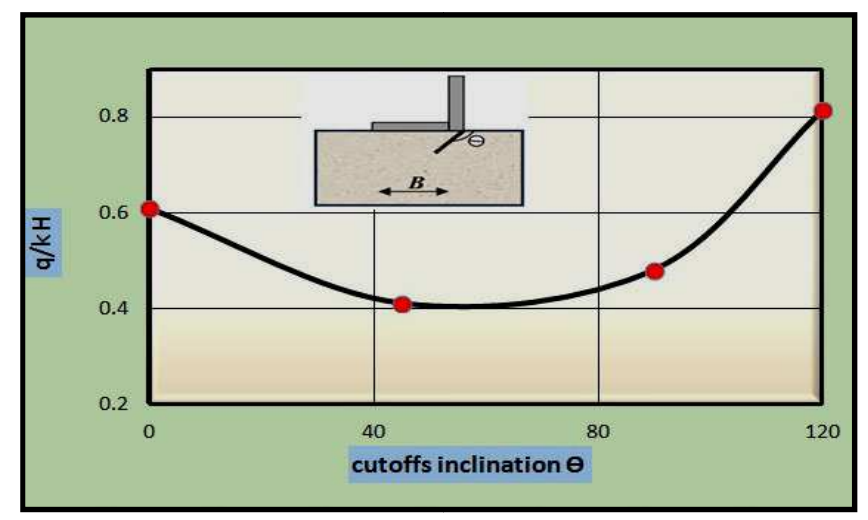

Figure (8). The Seepage quantity a range of different values $(\theta)$ for cutoff in U/S part of structure.

In figure(9) When the Cutoff is in upstream side of hydraulic structure the seepage decreases while $(\Theta)$ increases, and the least quantity of seepage occurred when $(\Theta)$ value around (120), then the seepage increases rapidly for $(\Theta \leq 90)$.

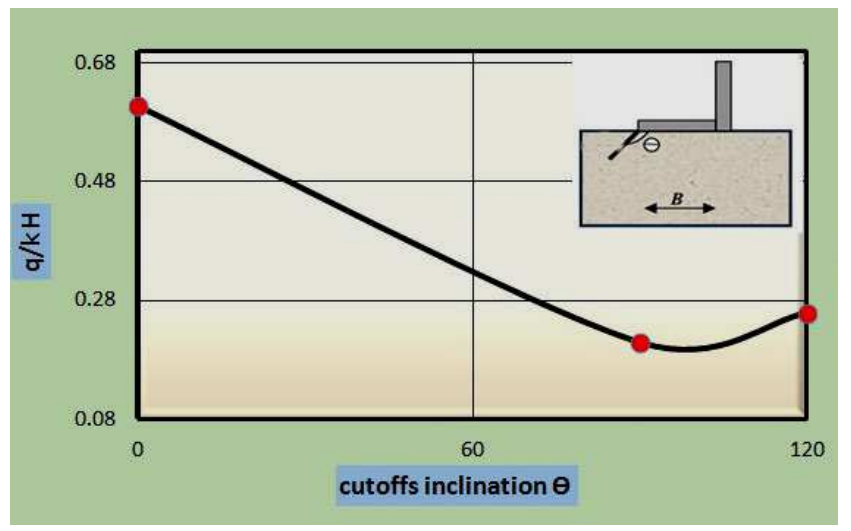

Figure (9). The Seepage quantity a range of different values $(\theta)$ for cutoff in $D / S$ part of structure.

\section{Conclusions}

The following main conclusions can be drawn from the results presented in this research:

The shapes of the flow net depend upon many factors such as diameter of the particle of the soil and location of cutoff.

The minimum value of uplift pressure is obtained when the cutoff used in upstream part of hydraulic structure with angle of inclination $\left(\Theta=45^{\circ}\right)$. That given redaction in value of uplift pressure according to the general case $\Theta=0$ was $53 \%$.

The minimum value of exist gradient is obtained when the cutoff used in downstream part of hydraulic structure with angle of inclination $\left(\Theta=120^{\circ}\right)$ That given redaction in value of exist gradient according to the general case $\Theta=0$ was $9.3 \%$. 
And increasing the factor of safety against piping to 2.06.

Placing the cutoff at the dam heel (cutoff U/S side) to reduce the piping phenomenon in downstream side is not recommended under any angle of inclination, because such placement has too small effect.

The best angle of inclination is $45^{\circ}$ towards upstream where it reduced the uplift pressure to ( $43 \%$ according to general case $\mathrm{\Theta}=0$ ) as compared with other type of inclination and reducing the quantity of seepage.

\section{References}

[1] AL-Ganaini, M.A., (1984), "Hydraulic Structure", Beirut, pp47-60, (In Arabic).

[2] Selim, M.A., (1947) "Dams on Porous Media", Transaction ASCE, Vol. 1 Roy, S.K. (2010). "Experimental Study On Different Types Of Seepage Flow Under The Sheet Pile Through Indigenous Model." M.Sc. Thesis Insoil Mechanics and Foundation Engineering, University Of Jadavpur.12, pp 488-526.

[3] Arslan, C. A. And Mohammad, S. A. (2011)."Experimental and Theoretical Study for Pizometric Head Distribution under Hydraulic Structures." Department of Civil engineering; College of engineering, University of kirkuk Volume 6, No.
[4] EL-Fitiany, M. A. Abourohim, R. I. And El-Dakak, A. Y. (2003). "Three dimensional ground water seepage around a simple hydraulic structure." Alexandria Engineering Journal, Volume 42, Issue 5, September.

[5] Roy, S.K. (2010). "Experimental Study On Different Types Of Seepage Flow Under The Sheet Pile Through Indigenous Model.", M.Sc. Thesis Insoil Mechanics and Foundation Engineering, University Of Jadavpur

[6] Aziz, L. J. (2008). "Lateral Resistance of Single Pile Embedded in Sand with Cavities.", D.Ph Thesis, University of Technology, Iraq.

[7] Khasaf, S. I.(1998). "Numerical Analysis of Seepage Problems with Flow Control Devices Underneath Hydraulic Structures." Ph.D. Thesis in Water Resources Engineering, University of Technology.

[8] U.S. Bureau of Reclamation.(1977). " Design of Small Dams." A Water Resources Technical Publication, Washington, DC.

[9] HM 169 (2011). "Drainage and Seepage Tank."Experiment Instructions Equipment for Engineering Education G.U.N.T. Gerätebau GmbH, Barsbüttel, Germany.

[10] Harr, M.E.(1962). "Groundwater and seepage." McGraw-Hill Book Company. 